\title{
Ready, willing, and able? USDA field staff as climate advisors
}

\author{
S. Wiener, G.E. Roesch-McNally, R.E. Schattman, and M.T. Niles
}

\begin{abstract}
Natural resource advisors operate at a natural resource-climate nexus that presents opportunity for utilization of regionally relevant climate science and tools to support climate smart decision making among land managers. This opportunity, however, may be underutilized. In thousands of county offices across the country, USDA field staff with the Natural Resources Conservation Service (NRCS) and Farm Service Agency (FSA) interface with farmers on a daily basis to provide conservation technical assistance, farm loans, and disaster recovery assistance. In this study, we conducted a survey of NRCS field staff $(n=1,893)$ and a similar survey of FSA field staff $(n=4,621)$ to determine the following: (1) how concerned USDA field staff are with both general and specific climate and weather threats and their effect on agriculture and forestry, (2) what available climate and weather resources staff are currently using, (3) how these factors relate to USDA field staff's confidence and interest in playing the role of climate advisor, and (4) the differences that exist between NRCS and FSA field staff related to these research questions. We found that many USDA field staff are concerned about climate change in general and about several specific impacts, but fewer are confident in their ability to support land managers in addressing these impacts. Additionally, increased concern about climate threats was related to higher levels of climate and weather resource use and an increased desire to play the role of climate advisor, but was also related to lower levels of self-reported ability to play that role. These findings can be used to inform appropriate application of professional development opportunities and creation of tools and resources to improve professional uses of weather and climate information.
\end{abstract}

Key words: agricultural advisor-climate change adaptation-extreme weather-Farm Service Agency - Natural Resources Conservation Service - weather and climate tools

Global climate change is causing or expected to cause increases in extreme events such as heavy rainfall, drought, and heat waves, in addition to impacting crop and tree phenology, growing season length, pest cycles, and more (USGCRP 2017). These climate impacts will have serious consequences for US agriculture and forestry, including potential crop losses, an increase in pest and disease prevalence, more frequent and extreme wildfires, and increased stress on livestock. These stressors may impact food security and natural resource livelihoods (USGCRP 2017). Addressing these impacts will require changes in the agricultural and natural resources sectors to mitigate risks and capitalize on potential benefits. A growing body of research focuses on understanding the beliefs of advisors who work with land managers (hereafter referred land managers, including guidance on how to weigh climate risks and take adaptive action (Hibbs et al. 2014; Lemos et al. 2014; Wojcik et al. 2014; Church et al. 2018). To be an effective climate advisor, one must commit substantial time to "finding, understanding, translating, and communicating a variety of data and tools and identifying past, present, and future weather and climate conditions" (Haigh et al. 2015). Playing the role of climate advisor presents institutional and personal challenges related to accessing current information and building the knowledge and capacity to apply climate and weather tools to specific agronomic and other natural resource based decision making contexts (Hibbs et al. 2014; Wojcik et al. 2014). Organizations such as the USDA Climate Hubs have recently emerged to support advisors in developing this capacity, recognizing that advisors play a crucial role in land managers' decision making. However, there is a dearth of information about how advisors engage with climate information in their professional duties (Church et al. 2018). Even less is known about advisors from USDA agencies, particularly field staff who work for the USDA Farm Service Agency (FSA) and Natural Resources Conservation Service (NRCS). These agencies have staff in agricultural service centers assisting land managers across the United States, but existing studies on these two agencies are regional, rather than national, in scope (Prokopy et al. 2013; Haigh et al. 2015; Church et al. 2018). The current study explores the climate perceptions and professional behaviors of more than 6,000 USDA employees who work directly with land managers, hereafter referred to as "field staff." We do so through two national surveys that provide insight into their willingness and confidence in playing the role of climate advisor. advisors have emerged as potentially critical players in supporting adaptation efforts, as has the importance of assessing their perspectives on climate related issues, particularly related to service provision in public and private sectors.

Advisors act as intermediaries between land managers and developers of the science and technology meant to improve land management practices and decision making (Haigh et al. 2015). As intermediaries, advisors have the potential, even if not always realized, to play a role in sharing climate and weather information with
Sarah Wiener is a research fellow, USDA Forest Service, Southeast Climate Hub, Raleigh, North Carolina. Gabrielle E. Roesch-McNally is the director of the Woman for the Land Initiative, American Farmland Trust, Corvallis, Oregon. Rachel E. Schattman is a research fellow, USDA Forest Service, Northeast Climate Hub and The University of Vermont Extension, Burlington, Vermont. Meredith T. Niles is an assistant professor, Food Systems Program and Department of Nutrition and Food Sciences and Food Systems Program, The University of Vermont, Burlington, Vermont. 
Roles of Natural Resources Conservation Service and Farm Service Agency Field Staff. NRCS and FSA field staff represent an important group of advisors with a potentially influential position among land managers due to their role in providing assistance with conservation practice implementation, crop insurance, and disaster recovery, and thus may be ideal candidates for the important role of intermediary between scientists, climatologists, and land managers. NRCS and FSA are home to the largest USDA conservation programs and work closely with land managers. Both agencies administer programming that strives to balance conservation and production goals.

NRCS pursues this dual mission through resource assessments and inventories, technology transfer, and technical assistance with implementation of conservation practices. For example, the Environmental Quality Incentives Program (EQIP) provides land managers with both one-on-one technical assistance and financial incentives to put conservation practices into place. These practices often also help land managers meet production goals (USDA NRCS 2018a). The NRCS process for implementing conservation practices involves identification of resource concerns important to a specific landowner from a preexisting list, many of which are related to weather and climate stressors either directly (e.g., insufficient water or excess water) or indirectly (e.g., soil erosion and inadequate feed and forage) (USDA NRCS 2017).

FSA is involved in the administrative aspects of many conservation programs for which NRCS provides technical support. FSA also provides disaster payments to land managers through indemnity programs and provides competitive infrastructure loans. Programs such as the Livestock Indemnity Program (LIP) and the Noninsured Crop Disaster Assistance Program (NAP) help reduce the risks land managers face from extreme weather-related loss, thereby providing market stability in participating agricultural sectors. Both agencies have significant presence in rural communities. Through the administration of a breadth of financial and conservation programs, hundreds of thousands of farmers interact with USDA field staff each year (USDA NASS 2014), providing many opportunities to share information on climate and weather related risk. Within FSA, there are 51 state offices and 2,124 county offices across the country including US Territories (USDA FSA 2017), while NRCS has 2,900 service centers and 12,000 employees, in addition to over 20,000 nonemployees who volunteer annually (USDA NRCS 2018b). Because both agencies have a long history of frequent and direct interaction with land managers throughout the country, field employees are well positioned to deliver services that support the overlapping goals of conservation and climate-adaptation while still promoting productivity.

Given that NRCS and FSA play different roles in agricultural service provision and interact with different, though overlapping, groups of farmers, it is important to examine the differences between these agencies. Many NRCS employees spend a significant amount of time in the field working with land managers on long-term conservation projects, providing technical assistance that is often directly or indirectly tied to weather and climate variability. FSA agents spend more time in the office processing claims and loans, but will also interact with more landowners than many NRCS employees in a given year, and often immediately after an extreme weather event or natural disaster. Furthermore, USDA Secretary Sonny Perdue announced in 2017, "the standing up of a newly named Farm Production and Conservation mission area to have a customer focus and meet USDA constituents in the field" (USDA 2017), which aligns NRCS and FSA under the same mission area. In the context of this reorganization, it is important to understand how the roles and training needs of employees in each agency vary in relation to climate change adaptation, even as mission areas converge.

In addition to the two agencies playing distinct roles, these staff also operate in a field that includes a diversity of agricultural advisors, including cooperative extension agents and crop advisors, as well as industry stakeholders such as seed and fertilizer dealers. Most farmers consider information from a mix of these various actors when making management and conservation decisions (Stuart et al. 2018). However, not all agricultural advisors are trusted equally in all subject areas. For example, a study of Iowa farmers showed that fewer than 25\% reported trusting federal agencies when it came to climate-related information (Arbuckle et al 2015), while a study of Northwest cereal farmers found that only 35\% of respondents trusted NRCS (Borelli et al. 2018). However, a survey of Midwestern agricultural advisors found that over half of advisors surveyed trust NRCS employees when it comes to climate information (Prokopy et al. 2015a). Further, mistrust of a source does not mean their information is ignored, but may be treated with skepticism and thus combined with information from other sources. This was found to be true in a study of Midwestern farmers' use of nitrogen (N) management information from public and private sector sources (Stuart et al. 2018).

Advisors, Climate Change, and Adaptation Support. Researchers have found that most advisors share similar worldviews and political leanings with the land managers they serve, presenting opportunities for dialogue but also presenting challenges to delivering science-based information on contentious issues such as climate change (Wojcik et al. 2014; Prokopy et al. 2015b; Schattman et al. 2018). Terms like "weather variability" or "climate variability" are often used to sidestep the politically charged language of climate change in an attempt to overcome some of these challenges associated with discussing climate change impacts and adaptation, and recent research has found that this language is more likely to reach advisors than that of "climate change," (Church et al. 2018). However, Prokopy et al. (2015a) found that three quarters of surveyed advisors believe climate change is happening. The majority of respondents in that study, which included NRCS employees, also agreed that their role as an advisor is to help land managers prepare for the impacts associated with increased weather variability. Other research focused on university extension finds similarly positive attitudes toward supporting farmers and other land managers in adapting to climate change (Templeton et al.2014; Wojcik et al. 2014). Therefore, despite persistent skepticism among land managers and advisors regarding anthropogenic climate change (Prokopy et al. 2015b), an opportunity exists to increase consideration of climate change impacts when making land management decisions.

Advisors' use of climate and weather tools is not only driven by their beliefs around climate change and climate-related risks. Their use of tools may also relate to the utility of these tools, as well as access to and awareness of them (Breuer et al. 2011). Lemos et 
al. (2014) found that the following three factors are critically important when assessing whether advisors will use climate information: (1) the presence of organizational support, (2) collaboration and information seeking behavior of individual advisors, and (3) their perceptions of long-term climateand weather-associated risks. Further, Haigh et al. (2015) found that advisors who specialize in providing agronomic information as part of their advisory role were positively inclined toward providing additional weather and climate information, and that many who focus specifically on conservation practices were already using weather and climate information when providing advice. Those providing direct financial guidance were less likely to utilize climate and weather tools in their advisor role. There is clear evidence that "advisors prefer to operate within their particular field of expertise, where their efficacy for assisting producers to adapt in a particular way can be expected to be at its highest" (Church et al. 2018).

Aims. The work presented in this paper aims to help us better understand agricultural advisors from USDA service centers by asking the following key questions:

1. How concerned are USDA field staff with both general and specific climate and weather risks and their effect on agriculture and forestry?

2. What available climate and weather resources are staff currently using?

3. How do these factors relate to USDA field staff's confidence and interest in playing the role of climate advisor?

4. What differences exist between NRCS and FSA field staff related to these research questions?

To answer these questions, we present results from two national surveys conducted of NRCS and FSA employees.

\section{Materials and Methods}

Survey Background. Two surveys were developed and administered collectively by the USDA Climate Hubs and the University of Vermont, in partnership with FSA and NRCS. The surveys were adapted, with permission, from the Useful to Useable project (https://mygeohub.org/groups/u2u; Prokopy et al. 2013). The FSA and NRCS survey content followed the same themes, but some of the questions varied slightly to reflect the unique missions and program areas of the two agencies. Examples of variations between the surveys included questions about the types of management decisions advisors discussed with land managers and the types of tools and resources respondents use.

The names and email addresses for over 8,000 NRCS employees and 10,000 FSA employees were gathered from a publicly available directory of USDA Service Centers. The distribution list was filtered based on job title to include only those who work directly with land managers. Staff were notified of the survey and encouraged to participate by leadership within their respective agencies. Three invitations to participate were sent via email, one week apart, following the Tailored Design Method (Dillman and Smyth 2014). The FSA survey was conducted in November and December of 2016, and the NRCS survey was conducted in February and March of 2017. The response rates for FSA and NRCS were $43 \%(n=4,621)$ and $22 \%(n=$ $1,893)$, respectively, calculated using Version 4.0 of the American Association of Public Opinion Research response rate calculator (AAPOR 2016).

Data Analysis and Variable Description. To more clearly articulate our analysis, we distilled our first three research questions into the following themes: concern, preparedness, and climate advisor interest (table 1). We began with descriptive statistics and comparative tests to examine differences between the two agen- cies, which are described in greater detail in the sections below. We then used a series of three multinomial logistic regression models to analyze how respondents' agreement with statements about service provision and weather variability related to their use of climate and weather resources, concern about climate and weather threats, their beliefs surrounding climate change, and other agency and demographic variables.

Concern. Respondents were asked to indicate their level of concern with a series of climate and weather stressors on a four-point Likert-type scale (e.g., increased soil erosion and longer dry periods and droughts) (see table 2 for description of scale). We report results at the national level and in terms of the most common climate concern for each state. Concerns about which we asked both agencies were then averaged for each respondent into a single variable on a 0 to 3 scale for inclusion in the models (table 2). Concerns included in this variable were those about disease, erosion, flooding, heat stress on livestock, heat stress on crops, dry periods and drought, excess moisture, frequent extreme rains, insects, and weeds. Respondents were also asked about their level of agreement with a series of general statements related to climate change and weather variability. Responses were on a five-point Likert scale from "strongly disagree" to "strongly agree."

Preparedness. Preparedness for climate and weather related threats was measured by examining respondents' use of climate and weather resources from three sets of questions, each of which involved evaluating a list of resources or topics related to that question (see Wiener et al. 2018 for a full list of resources and topics):

1. Do you use the following weatherrelated resource?

2. Do you consider historical weather trends and/or forecasts when you discuss the following topics with producers?

\section{Table 1}

Research questions and associated themes.

\begin{tabular}{ll}
\hline Theme & Research question \\
\hline Concern & How concerned are USDA field staff with both general and specific climate and weather threats and their effect on \\
& agriculture and forestry? \\
Preparedness & What available climate and weather resources are staff currently using? \\
Climate advisor interest & How do these factors relate to USDA field staff's confidence and interest in playing the role of climate advisor? \\
Agency role & What differences exist between Natural Resources Conservation Service (NRCS) and Farm Service Agency \\
& (FSA) field staff related to these research questions?
\end{tabular}




\section{Table 2}

Definition of variables and variable values.

\begin{tabular}{|c|c|c|}
\hline Variable name & Survey statement & Values \\
\hline \multicolumn{3}{|c|}{ Dependent variables } \\
\hline \multicolumn{3}{|c|}{ Theme: Climate advisor interest } \\
\hline Commitment to support & $\begin{array}{l}\text { "In my current role, I should help producers to prepare } \\
\text { for increased weather variability," (FSA) or, "Assisting } \\
\text { producers to prepare for increased weather variability } \\
\text { is part of my job." (NRCS) }\end{array}$ & $\begin{array}{l}1=\text { strongly disagree/disagree; } \\
2 \text { = neither agree nor disagree; } \\
3 \text { = strongly agree/agree. }\end{array}$ \\
\hline Knowledge & $\begin{array}{l}\text { "I have the knowledge and technical skill to help producers } \\
\text { deal with any weather-related threats to the viability of } \\
\text { their operation." }\end{array}$ & $\begin{array}{l}1=\text { strongly disagree/disagree; } \\
2 \text { = neither agree nor disagree; } \\
3 \text { = strongly agree/agree. }\end{array}$ \\
\hline Confidence & $\begin{array}{l}\text { "I am confident in my ability to apply weather forecasts } \\
\text { and information to the services I provide." }\end{array}$ & $\begin{array}{l}1 \text { = strongly disagree/disagree; } \\
2 \text { = neither agree nor disagree; } \\
3 \text { = strongly agree/agree. }\end{array}$ \\
\hline
\end{tabular}

Independent variables

Theme: Preparedness

Tool use count

Do you use the following weather related resource?

Summated scale of eight resources: $0=$ don't use OR not familiar with; $1=$ use. Final variable on 0 to 8 scale.

Weather information dependence

How dependent are you on the following types of weather information to do your job?

Average of dependence on seven time scales of weather information: $0=$ not dependent; 1 = somewhat dependent; 2 = dependent; 3 = very dependent. Final variable on 0 to 3 scale.

Theme: Concern

Climate concern

"Please indicate your level of concern with the following weather related impact."

Average concern for 10 types of impacts: $0=$ not concerned; 1 = somewhat concerned; 2 = concerned; 3 = very concerned. Final variable on 0 to 3 scale.

Climate belief

"Please select the statement that best indicates your beliefs about climate change."

1 = climate change is not occurring; 2 = climate change is occurring, causes are mostly natural; $3=$ insufficient evidence to know; 4 = climate change is occurring, driven equally by human and natural causes; 5 = climate change is occurring driven mostly by human causes.

Demographic variables

$\begin{array}{ll}\text { Agency } & \text { Agency the respondent works for } \\ \text { Gender } & \text { Gender of respondent } \\ \text { Age } & \text { Age of respondent }\end{array}$

Education

Education of respondent

$0=$ FSA 1 = NRCS.

$0=$ male 1 = female.

$1=10$ to 19 years; $2=20$ to 29 years;

$3=30$ to 39 years; $4=40$ to 49 years;

$5=50$ to 59 years; $6=60$ to 69 years;

$7=70+$ years.

1 = No college; 2 = some college/ associates degree; 3 = four-year college degree; 4 = graduate degree.

Notes: NRCS $=$ Natural Resources Conservation Service. FSA = Farm Service Agency.

3. How dependent are you on the following types of weather information to do your job?

The variable names tool use, consider weather information, and weather information dependence, respectively, are used from this point forth (table 2).

For inclusion of tool use and weather information dependence in the model, two summary variables were created. A summated scale was used to summarize tool use. For weather information dependence, responses were averaged across the seven time scales about which respondents were asked.
Climate Advisor Interest. Respondents assessed a series of statements to indicate their level of agreement on a five-point Likert scale with topics related to climate and weather extremes, as well as a series of statements regarding service provision within a respondent's agency as related to climate and weather extremes. Descriptive statistics were reported for each statement, and responses were compared between NRCS and FSA respondents. Three of these statements were then collapsed from five categories into three categories (disagree, neutral, and agree) and used as the dependent variables for the three multinomial logistic regression models (table 2). These variables are commitment to support, knowledge, and confidence. Related to these variables, this study does not seek to determine if USDA field staff formally consider themselves to be climate advisors, but rather if they consider these services to currently be within the scope of their job responsibilities, if they are currently taking steps to provide these services, and how comfortable they are in that role.

Model Variable Choice. In order to inform the development of training activities and support for USDA field staff related to inte- 
gration of climate and weather information into their professional services, we seek to evaluate how climate advisor interest (encompassing the three variables of knowledge, confidence, and commitment to support) relates to concern and preparedness.

Related to concern, we sought to capture the variety of ways that respondents may experience and think about climate change and weather variability by including both the climate belief variable and the climate concern variable (table 2). The former may be influenced by respondents' world views, which have been shown to be aligned between land managers and the advisors who serve them (Wojcik et al. 2014; Prokopy et al. 2015b; Schattman et al. 2018), and by continued skepticism regarding anthropogenic climate change (Prokopy et al. 2015b). The latter captures the influence of acute and accumulated experiences that advisors have had throughout their professional career, specifically of the intersection between climate and weather and land management activities. Previous research suggests that these observations may have a stronger influence on risk perception than climate models and other statistical information (Marx et al. 2007).

The tool use and weather information dependence variables capture the ways that field staff may already be playing the role of climate advisor, whether they realize it or not. This represents the extent to which respondents have already invested in the task of identifying, understanding, and applying tools, and may have already recognized the substantial challenges associated with applying these tools in a professional setting (Hibbs et al. 2014; Wojcik et al. 2014; Haigh et al. 2015). For individuals who have made this investment, acting as a climate advisor may seem more attainable, or an appropriate outlet for new knowledge and skills acquired through the process of adopting these resources. Finally, the agency variable accounts for variation in mission, duties, roles, and time spent in the field and with land managers.

We used three categories (disagree, neutral, and agree) for the dependent variables, rather than collapsing into two categories (such as agree and do not agree), because the neutral group was a large proportion of the sample $(27 \%$ to $56 \%)$, and to capture any distinct characteristics in the neutral group that can inform how trainings and resources are developed.

\section{Results and Discussion}

Respondent Characteristics. NRCS respondents were mostly male (63\%) and white (75\%), while FSA respondents were primarily female $(68 \%)$ and white $(86 \%)$, which is reflective of the demographic profile of staff for both agencies. Both NRCS and FSA respondents worked for their agencies and for USDA for an average of 17 years (NRCS $s d=11$; FSA $s d=12)$. Close to two-thirds of NRCS respondents (65\%) and slightly fewer than half $(46 \%)$ of FSA respondents attained a four-year college degree as their highest educational achievement, with an additional $24 \%$ of NRCS respondents and $8 \%$ of FSA respondents also receiving a graduate degree.

Job titles most commonly reported by NRCS respondents were district conservationists (25\%) and soil conservationists (19\%), while the most common position titles for FSA respondents were program technician $(56 \%)$ and county executive director $(22 \%)$. The majority of FSA (92\%) and NRCS $(86 \%)$ respondents indicated that they regularly interact with land managers throughout the course of their professional duties. Those who did not were excluded from our analysis. Among NRCS respondents included in our analysis, 83\% work with farmers, 51\% work with ranchers, and 44\% work with forest landowners, with multiple responses allowed for this question. All NRCS respondents indicated that they primarily work with agricultural land managers, while FSA respondents were not asked specifically about the sectors they serve.

Concern. For respondents from both agencies, the average level of concern was highest for longer dry periods and droughts $(\mathrm{FSA}=2.82, \mathrm{sd}=0.92 ; \mathrm{NRCS}=2.91, \mathrm{sd}=$ 0.94 ; see table 2 for scale and figure 1 for full list of concerns). NRCS respondents ranked increased soil erosion $(2.70, \mathrm{sd}=0.97)$, increased weed pressure $(2.69$, sd $=0.94)$, and increased insect pressure $(2.55, \mathrm{sd}=0.92)$ as the second, third, and fourth highest concerns, respectively. Among FSA respondents, who were presented with a slightly different list of concerns, increased heat stress on crops (2.51, sd $=0.94)$, increased weed pressure (2.46, sd $=0.94)$, and increased heat stress on livestock $(2.42, \mathrm{sd}=0.92)$ were of the highest concern, after longer dry periods and droughts. When examined at the state/territorial level, most states/territories expressed the greatest concern about longer dry periods and droughts, though there was more variability between states within our sample of NRCS employees (figure 1). For example, NRCS respondents in the Northwest expressed concern for higher incidence of wildfire, while those respondents in the upper Midwest/Great Lakes area expressed concern with increased soil erosion.

NRCS respondents expressed higher concern than FSA respondents with most of the topics at statistically significant levels $(p<0.05)$. The mean difference between respondents from the two agencies in reported concern was greatest for increased soil erosion $\left(M_{\text {diff }}=\right.$ 0.42 ) and increased loss of manure into waterways $\left(M_{\text {diff }}=0.38\right)$. The topics for which FSA expressed higher concern than NRCS at statistically significant levels were, in descending order of mean difference, increased incidences of hail $\left(M_{\text {diff }}=0.20\right)$, increased heat stress on livestock $\left(M_{\text {diff }}=0.14\right)$ and on crops $\left(M_{\text {diff }}=\right.$ $0.03)$, and crop stress or loss due to frost or freeze $\left(M_{\text {diff }}=0.14\right)$. Among statements about climate change, weather variability, and land management, NRCS respondents expressed the most agreement with the need for producers to adapt to climate change to ensure the long-term success of US agriculture $(72 \%$ agree), forestry (71\% agree), and rangeland (69\% agree) (table 3). FSA respondents, who were not asked about forestry and rangeland specifically, expressed the greatest agreement with the same statement on the need for agricultural producers to adapt to climate change (65\% agree). Over half of respondents from both agencies agreed that they have noticed more variable or unusual weather in the past five years $(\mathrm{NRCS}=65 \%$; FSA $=59 \%$ ), that changing farming practices is important to cope with increasing climate variability $(\mathrm{NRCS}=67 \%$; FSA $=54 \%)$, and that producers should take additional steps to protect their operations from this increased variability. However, far fewer respondents from both agencies agreed that changes in weather patterns are hurting the producers in their service area $(\mathrm{NRCS}=38 \%$; FSA $=37 \%)$. NRCS respondents reported greater agreement with each statement in the table $(p<0.05)$ except, "Changes in weather patterns are hurting the producers in my service area."

Preparedness. The most common climate or weather related resource used by both agencies, and the only resource used by more than half of respondents from either agency, was the US Drought Monitor and/or Outlook (figure 2). The Livestock Heat Index, Farmer's Almanac, and satel- 


\section{Figure 1}

Most common climate or weather concern of (a) USDA Farm Service Agency (FSA; $n=3,571$ ) and (b) USDA Natural Resources Conservation Service (NRCS; $n=1,376$ ) respondents by state.

(a)

(a)

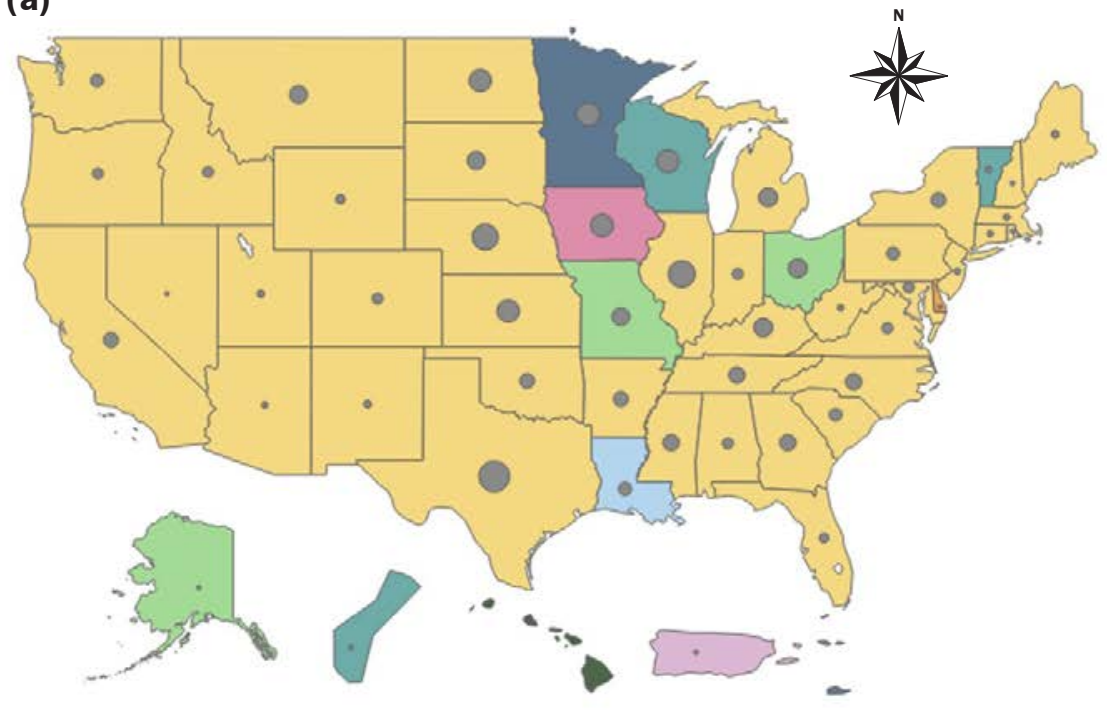

\section{Legend}

Longer dry periods and drought

Increased soil erosion

Higher incidence of tree pathogens

Higher incidence of wildfire

Increased weed pressure

More frequent extreme rain events

Excessive moisture

Increased flooding

Increased heat stress on crops/timber stands

Increased incidence of hurricanes or tropical depressions

Increased loss of nutrients into waterways

Increased pressure from animal species

Increased pressure from plant species

Increased insect pressure and higher incidence of

crop disease (tie)

(b)

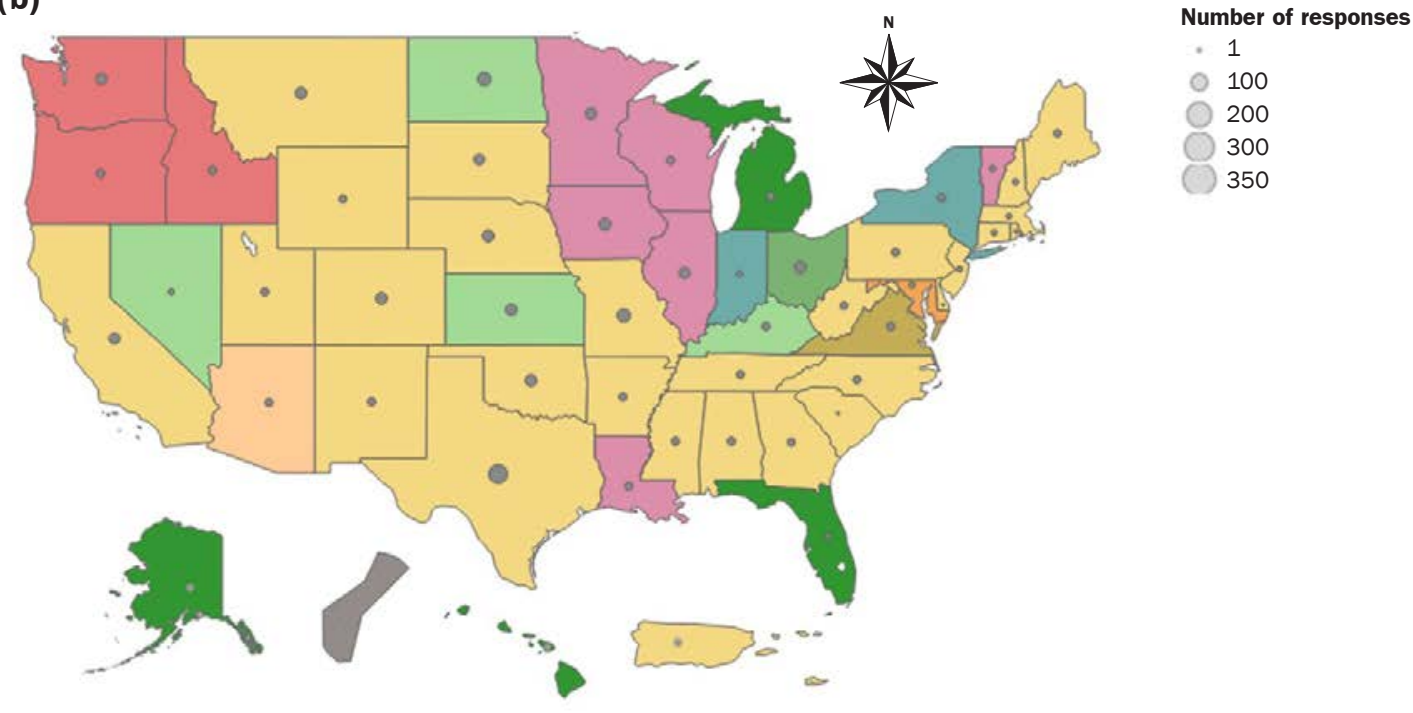

Number of responses

- 100

200

300

350

lite data were the second, third, and fourth most commonly used resources among FSA respondents, respectively. Among NRCS respondents, the tools most frequently used after the Drought Monitor and/or Outlook were growing degree day (GDD) tools, evapotranspiration indices, and satellite data. Many respondents from both agencies were not familiar with or did not use several of these weather-related tools, which could improve support when providing assistance to customers on weather and climate related threats. Among the least used tools were for- age dry down indices, crop disease forecasts, and insect forecasts, all of which were used by $17 \%$ or fewer respondents from both agencies. NRCS respondents reported use of most tools or resource more often than FSA respondents $(p<0.05)$. Exceptions include that FSA respondents reported greater use of the US Drought Monitor or Outlook and livestock heat indices/cattle heat stress forecast, and that there were no significant differences in use of the Crop Disease Forecast and Farmer's Almanac.
Regarding consideration of historical weather trends and/or forecasts when discussing various land management topics with producers, FSA respondents most often considered this information when discussing crop yields, purchasing crop insurance or NAP, and planting or harvest schedules, in descending order (table 4). The top three selections for NRCS respondents were in-field conservation practices, grazing and forage management, and tillage decisions. The use of historical weather trends and/or forecast information varied from between 10\% and 


\section{Table 3}

Agreement with statements about climate and weather extremes, producers, and adaptation.

\begin{tabular}{|c|c|c|c|c|c|}
\hline $\begin{array}{l}\text { Statement (sorted in order of } \\
\text { combined mean of both agencies) }\end{array}$ & Agency & Mean & Std. dev. & $\begin{array}{l}\text { Strongly agree/ } \\
\text { agree (\%) }\end{array}$ & $M_{\text {diff }} \dagger$ \\
\hline $\begin{array}{l}\text { It is important for producers to adapt to climate } \\
\text { change to ensure the long-term success of US forestry. }\end{array}$ & NRCS & 3.88 & 0.89 & 71 & - \\
\hline $\begin{array}{l}\text { It is important for producers to adapt to climate } \\
\text { change to ensure the long-term success of US rangeland. }\end{array}$ & NRCS & 3.79 & 0.97 & 69 & - \\
\hline $\begin{array}{l}\text { It is important for producers to adapt to climate } \\
\text { change and ensure the long-term success of US agriculture. }\end{array}$ & $\begin{array}{l}\text { NRCS } \\
\text { FSA }\end{array}$ & $\begin{array}{l}3.86 \\
3.71\end{array}$ & $\begin{array}{l}0.92 \\
0.84\end{array}$ & $\begin{array}{l}72 \\
65\end{array}$ & $0.15 * *$ \\
\hline $\begin{array}{l}\text { In the past five years, I have noticed more variable/ } \\
\text { unusual weather in my area. }\end{array}$ & $\begin{array}{l}\text { NRCS } \\
\text { FSA }\end{array}$ & $\begin{array}{l}3.79 \\
3.55\end{array}$ & $\begin{array}{l}1.12 \\
0.98\end{array}$ & $\begin{array}{l}65 \\
59\end{array}$ & $0.24 * *$ \\
\hline $\begin{array}{l}\text { To cope with increasing climate variability, changing } \\
\text { farming practices is important for the long-term success } \\
\text { of producers in my service area. }\end{array}$ & $\begin{array}{l}\text { NRCS } \\
\text { FSA }\end{array}$ & $\begin{array}{l}3.84 \\
3.52\end{array}$ & $\begin{array}{l}1.09 \\
0.92\end{array}$ & $\begin{array}{l}67 \\
54\end{array}$ & $0.32 * *$ \\
\hline $\begin{array}{l}\text { Producers should take additional steps to protect their } \\
\text { operations from increased weather variability. }\end{array}$ & $\begin{array}{l}\text { NRCS } \\
\text { FSA }\end{array}$ & $\begin{array}{l}3.74 \\
3.62\end{array}$ & $\begin{array}{l}0.86 \\
0.75\end{array}$ & $\begin{array}{l}68 \\
61\end{array}$ & $0.12 * *$ \\
\hline $\begin{array}{l}\text { To cope with increasing climate variability, changing } \\
\text { forestry practices is important for the long-term success } \\
\text { of the producers in my service area. }\end{array}$ & NRCS & 3.62 & 1.11 & 56 & - \\
\hline $\begin{array}{l}\text { Extreme weather events in recent years have affected the } \\
\text { long-term management goals of producers in my service area. }\end{array}$ & $\begin{array}{l}\text { NRCS } \\
\text { FSA }\end{array}$ & $\begin{array}{l}3.45 \\
3.28\end{array}$ & $\begin{array}{l}1.02 \\
0.96\end{array}$ & $\begin{array}{l}50 \\
42\end{array}$ & 0.17 ** \\
\hline $\begin{array}{l}\text { Changes in weather patterns are hurting the producers } \\
\text { in my service area. }\end{array}$ & $\begin{array}{l}\text { NRCS } \\
\text { FSA }\end{array}$ & $\begin{array}{l}3.26 \\
3.21\end{array}$ & $\begin{array}{l}1.06 \\
0.98\end{array}$ & $\begin{array}{l}38 \\
37\end{array}$ & 0.05 \\
\hline
\end{tabular}

Notes: Questions ranked on a five point Likert scale: (1) strongly disagree; (2) disagree; (3) neither agree nor disagree; (4) agree; (5) strongly agree. Questions adapted from Prokopy et al. (2013).

*Indicates significant difference in responses as determined by Mann-Whitney $U$ test at $p<0.05$.

$* *$ Indicates significant difference in responses as determined by Mann-Whitney $U$ test at $p<0.01$.

†A positive mean difference indicates that USDA Natural Resources Conservation Service (NRCS) respondents expressed greater agreement with a given topic, while a negative mean difference indicates that USDA Farm Service Agency (FSA) respondents expressed greater agreement with that topic.

$55 \%$ across the list of topics for FSA respondents, and between $22 \%$ and $73 \%$ for NRCS respondents. Overall, NRCS respondents reported use of historical weather data and weather/climate forecasts in discussing each comparable topic with producers significantly more often than FSA respondents $(p<0.05)$.

FSA and NRCS respondents reported being most dependent on current to near term weather conditions in their professional services, and less dependent on weather forecasts that report on longer timescales (e.g., six-month or seasonal forecasts) (figure 3). Regarding observed historical weather information, FSA employees reported greater reliance on weather data from the past 12 months, while NRCS employees were more likely to indicate dependence on historical weather trends (multiyear). Fewer than $20 \%$ of respondents from both agencies reported using annual or longer term outlooks. Overall, NRCS respondents reported significantly greater dependence than FSA respondents on each time scale of weather information listed in the survey $(p<0.05)$.

Climate Advisor Interest. Respectively, $45 \%$ and $42 \%$ of NRCS and FSA respondents agreed that there will be an increased need for agency programs in their service area due to changing weather patterns, and about half $(52 \%)$ of NRCS respondents agreed that assisting producers with increased weather variability is part of their job, while $29 \%$ of FSA respondents agreed that they should assist producers with increased weather variability as part of their current role (table $5)$. Over half of NRCS respondents (63\%) agreed that they would like climate or weather forecasts to inform client decisions, while $34 \%$ of FSA respondents agreed that they would like climate or weather forecasts to inform their service provision. For this topic, NRCS and FSA were presented with slightly different statements to reflect the different roles of the two agencies. Fewer than half of respondents from both agencies agreed that they are confident in their ability to apply weather forecasts and information to their services $(47 \%$ and $26 \%$ of NRCS and FSA respondents, respectively), and only $34 \%$ of NRCS respondents and 14\% of FSA respondents agreed that they have the knowledge and technical skills to help producers deal with any weather-related threats to the viability of their operation. NRCS respondents agreed with each of the comparable statements in table 5 more often than FSA respondents $(p<0.05)$ except the statement regarding increased need for NRCS/ FSA programs.
Next, we conducted a series of three multinomial logistic regressions to examine the relationship between respondents' perception of their professional duties regarding the provision of climate and weather related services, including their confidence in providing these services, with use of climate and weather resources, climate risk perception, perceptions of climate change, and demographic variables. The variables used in this analysis are presented in table 2 , and model output can be found in table 6 .

Agree versus Disagree. Across all three multinomial models, respondents who used more climate and weather tools $(p<0.001)$, reported a greater overall dependence on various time scales of weather information $(p<0.001)$, worked for NRCS $(p<0.01)$, and were younger than their peers $(p<0.05)$ were more likely to agree with each of the dependent variable statements (knowledge, confidence, and commitment to support) than to disagree with those statements (table 6). Those who reported beliefs that are closer to scientific consensus on climate change and who expressed greater climate concern were more likely to agree with the commitment statement, but were more likely to disagree with the knowledge statement $(p<$ 0.001). While those with lower climate concern 


\section{Figure 2}

A comparison of USDA Natural Resources Conservation Service (NRCS) and USDA Farm Service Agency (FSA) responses to "Do you use the following weather-related resource?" Top five resources are shown from a list of nine, in descending order of mean use among both agencies. Question from Prokopy et al. (2013).

US Drought Monitor or Outlook**

Livestock Heat Index** Cattle Heat Stress Forecast

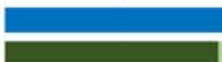

Growing Degree Day tools**

Farmers Almanac

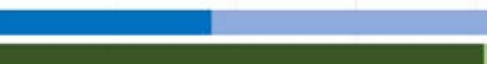

Farmers Almanac

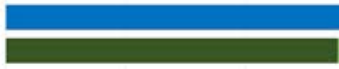

Satellite data**

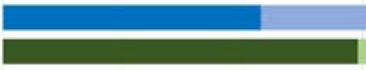

Evapotranspiration Index**

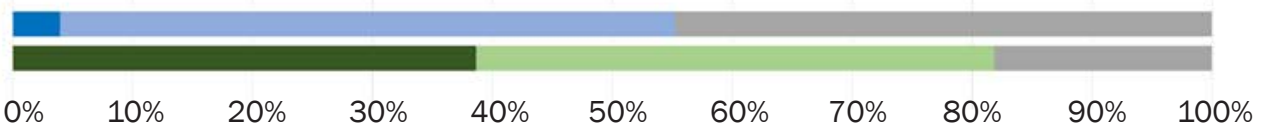

\section{Legend}

FSA responses (top bars)

Use Don't use

\section{NRCS responses (bottom bars)}

Unse Don't use

Not familiar with

*Indicates significant difference in use between the two agencies at $p<0.05$.

**Indicates significant difference in use between the two agencies at $p<0.01$.

\section{Table 4}

Responses to "Do you consider historical weather trends and/or forecasts when you discuss the following topics with producers?" Top five responses of 16 (USDA Farm Service Agency [FSA]) or 17 (USDA Natural Resources Conservation Service [NRCS]) for each agency displayed.

\begin{tabular}{|c|c|c|c|}
\hline NRCS top five & $\begin{array}{l}\text { Using weather } \\
\text { information (\%) }\end{array}$ & FSA top five & $\begin{array}{l}\text { Using weather } \\
\text { information (\%) }\end{array}$ \\
\hline In-field conservation practices & 73 & Crop yields & 55 \\
\hline Grazing and forage management & 71 & $\begin{array}{l}\text { Purchasing crop insurance or Noninsured } \\
\text { Crop Disaster Assistance Program (NAP) }\end{array}$ & 51 \\
\hline Tillage decisions & 67 & Planting or harvest schedule & 42 \\
\hline Livestock management & 64 & Market information & 38 \\
\hline On-farm water management systems & 60 & Crop and commodity storage & 37 \\
\hline
\end{tabular}

were also more likely to agree with the confidence statement $(p<0.01)$, climate belief was not significant in this model. Respondents with higher levels of formal education were more likely to agree with the commitment $(p$ $<0.01)$ and knowledge $(p<0.001)$ statements, but education was not significant for the confidence statement. Those who agreed with the knowledge $(p<0.001)$ and confidence $(p$ $<0.05)$ statements were more likely to be male, but gender was not significant for the commitment statement.

Neutral versus Disagree. The neutral group was similar to the agree group when compared to the disagree group across all three dependent variables. Fewer variables were significant, and overall significance and effect size was generally lower, but directionality was the same across all significant variables with one exception. While respondents from NRCS were more likely to agree than disagree with the confidence statement, respondents from FSA were more likely to be neutral than disagree with that same statement. Notably, climate concern and climate belief were significant across all three models.

Discussion. Based on our large nationwide surveys of NRCS and FSA advisors, key findings include the following: (1) many respondents from both agencies are concerned about climate change and weather variability in general, but fewer are confident in their ability to address these impacts; (2) many tools and resources that could be used to support climate-informed decision making are used by few respondents from both agencies, but those who do use them are more likely to agree with or be neutral on the commitment, knowledge, and confidence statements; and (3) those who report having the knowledge and confidence to assist with future weather variability tend to have lower climate concern and hold beliefs that are farther from scientific consensus on climate change, while the opposite is true for those who are committed to helping farmers prepare for increased weather variability.

On Concern. Employees within both agencies exhibit strong agreement that producers will need to adapt to climate change and that they should take steps to protect their 


\section{Figure 3}

Responses to "How dependent are you on the following types of weather information to do your job?" Options in chronological order, beginning with forecasts and ending with observations. Question from Prokopy et al. (2013).

Current weather conditions**

1 to 7 day forecasts**
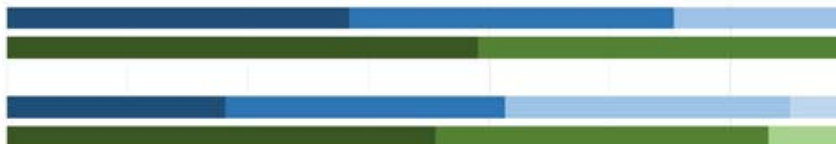

Historical weather trends**

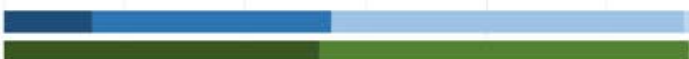

8 to 14 day outlooks**

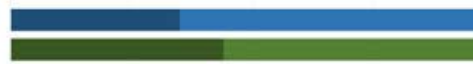

Monthly or seasonal outlooks**

Weather data for the past 12 months **

Annual or longer term outlooks**

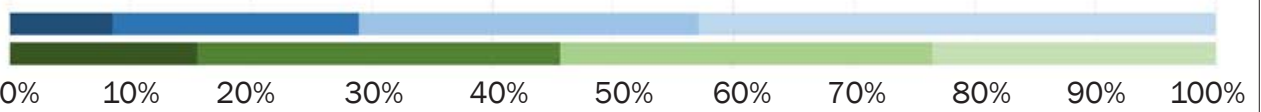

Legend

FSA responses (top bars)

- Very dependent

NRCS responses (bottom bars)

Very dependent

Moderately dependent

Moderately dependent

M Slightly dependent

Not dependent

= Slightly dependent

Not dependent

*Indicates significant difference in use between the two agencies at $p<0.05$.

$* *$ Indicates significant difference in use between the two agencies at $p<0.01$.

Table 5

Agreement with statements about service provision.

\begin{tabular}{|c|c|c|c|c|c|}
\hline $\begin{array}{l}\text { Statement (sorted in order of } \\
\text { combined mean of both agencies) }\end{array}$ & Agency & Mean & Std. dev. & $\begin{array}{l}\text { Strongly agree/ } \\
\text { agree (\%) }\end{array}$ & $\boldsymbol{M}_{\text {diff }} \dagger$ \\
\hline $\begin{array}{l}\text { I would like climate or weather forecasts } \\
\text { to inform the client decisions. }\end{array}$ & NRCS & 3.70 & 0.84 & 63 & - \\
\hline $\begin{array}{l}\text { I would like climate or weather forecasts } \\
\text { to inform the services I provide. }\end{array}$ & FSA & 3.21 & 0.83 & 34 & \\
\hline $\begin{array}{l}\text { I believe there is an increased need for FSA/NRCS programs } \\
\text { in my service area due to changing weather patterns. }\end{array}$ & $\begin{array}{l}\text { NRCS } \\
\text { FSA }\end{array}$ & $\begin{array}{l}3.34 \\
3.31\end{array}$ & $\begin{array}{l}1.10 \\
0.98\end{array}$ & $\begin{array}{l}45 \\
42\end{array}$ & 0.03 \\
\hline $\begin{array}{l}\text { Assisting producers to prepare for increased weather } \\
\text { variability is a part of my job. }\end{array}$ & NRCS & 3.44 & 0.95 & 52 & $0.39 * *$ \\
\hline $\begin{array}{l}\text { In my current role, I should help producers to prepare } \\
\text { for increased weather variability. }\end{array}$ & FSA & 3.05 & 0.88 & 29 & \\
\hline $\begin{array}{l}\text { I am confident in my ability to apply weather forecasts and } \\
\text { information to the services I provide. }\end{array}$ & $\begin{array}{l}\text { NRCS } \\
\text { FSA }\end{array}$ & $\begin{array}{l}3.38 \\
3.04\end{array}$ & $\begin{array}{l}0.90 \\
0.81\end{array}$ & $\begin{array}{l}47 \\
26\end{array}$ & $0.34 * *$ \\
\hline $\begin{array}{l}\text { I have the knowledge and technical skill to help producers } \\
\text { deal with any weather-related threats to the viability }\end{array}$ & $\begin{array}{l}\text { NRCS } \\
\text { FSA }\end{array}$ & $\begin{array}{l}3.62 \\
2.63\end{array}$ & $\begin{array}{l}1.11 \\
0.89\end{array}$ & $\begin{array}{l}56 \\
14\end{array}$ & $0.44 * *$ \\
\hline
\end{tabular}

of their operation.

Notes: Questions ranked on a five point Likert scale: (1) strongly disagree; (2) disagree; (3) neither agree nor disagree; (4) agree; (5) strongly agree. Questions adapted from Prokopy et al. (2013).

* Indicates significant difference in responses as determined by Mann Whitney $U$ test at $p<0.05$

**Indicates significant difference in responses as determined by Mann-Whitney $U$ test at $p<0.01$

†A positive mean difference indicates that USDA Natural Resources Conservation Service (NRCS) respondents expressed greater agreement with a given topic, while a negative mean difference indicates that USDA Farm Service Agency (FSA) respondents expressed greater agreement with that topic.

operations from increased weather variability. Surprisingly, there was greater agreement from respondents within both agencies with statements on the need to adapt to climate change than with statements on the need to adapt to increased climate variability. This finding seems to contradict a recent study that found "climate variability" and "extreme weather concerns" resonate more with advisors than "climate change" (Church et al.
2018). However, much lower agreement was found with the statements that discuss current impacts on land managers, which suggests that some employees may see climate change as a future problem, rather than 
Table 6

Multinomial logistic regression of factors related to a respondent's commitment to support, knowledge, and confidence.

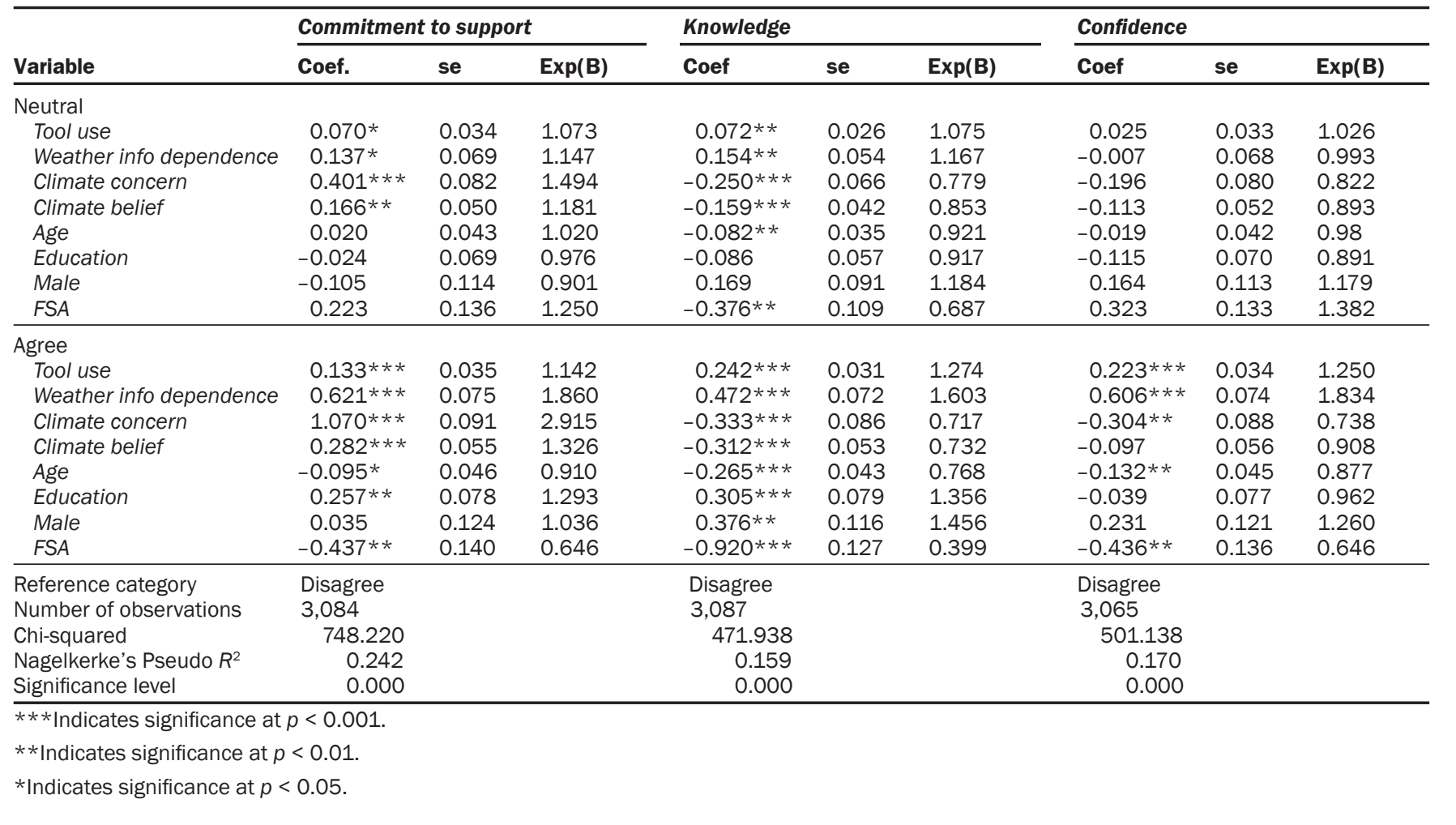

one that is impacting their producers now. This finding is in alignment with previous research on advisors' (Haigh et al. 2015) and other land managers' concerns (Carlton et al. 2016; Morton et al. 2017). Advisors may not tie specific extreme events or even shifting trends in climatological patterns to a changing climate. Additionally, for some advisors, their level of uncertainty in whether or not climate change is occurring and how it might impact producers they work with may be associated with "a perceived inability to provide useful advice to producers" on the topic of climate resilience (Church et al. 2018). High levels of uncertainty have been shown to discourage climate adaptation efforts among land managers as well (Morton et al. 2017). Further, lack of concern about climate change can have many causes, such as ideology, religion, and self-protection (Lucas and Davison 2018). Identifying the need to adapt in the future, however, may still influence the services that USDA field staff provide. For example, Lemos et al. (2014) found that advisors who more strongly agree that their clients will need to change practices to cope with increasing climate variability were also more likely to provide advice based on climate information.
Drought, which was the most common climate concern for respondents from both agencies, is a resource concern commonly dealt with by NRCS field staff through soil and water conservation programming, while FSA agents administer disaster payments due to drought through multiple indemnity programs. Beyond drought, it is particularly enlightening that significant differences were found between NRCS and FSA respondents regarding the types of threats about which they are concerned. NRCS respondents were significantly more concerned about soil erosion and increased loss of manure into waterways, which are both closely tied into the conservation programs they administer. FSA respondents were significantly more concerned about hail, heat stress, and frost or freeze. Each of these are specific categories of crop insurance administered by FSA. This finding suggests that field staff may see climate and weather threats through the lens of the professional services they administer, which is supported by Marx et al. (2007). The importance of this finding is underscored by the strong relationship between climate concern and commitment to support.

On Preparedness. Although many climate and weather resources are underutilized by USDA field staff, usage rates are similar to those found in other studies (Prokopy et al. 2013; Haigh et al. 2015). Further, our findings suggest that NRCS respondents use tools and resources and integrate climate and weather data into their professional services more often than FSA respondents, which is similar to the findings of Haigh et al. (2015). A notable exception is the US Drought Monitor or Outlook and livestock heat indices, which were used more frequently by FSA respondents. Both tools directly relate to indemnity programs that are administered through FSA, which aligns with the findings of Bruer et al. (2011) that use of these tools is related to their utility and accessibility, and suggests the possibility that FSA staff may be receptive to using additional climate related tools and resources if they can directly inform or streamline professional duties.

Although NRCS employees report utilizing tools and data that may provide climate and adaptation information to land managers more than FSA employees, it is more likely that an individual land manager will interact with an FSA employee than an NRCS employee. FSA administers the programs most commonly utilized by land managers including low cost farm loans, certain types of crop insurance, indemnities, and disaster payments, while NRCS administers 
less utilized programs focused on voluntary conservation efforts. For example, the most recently available USDA Census data suggest that in 2012, more than 780,000 principal operators participated in nonconservation-oriented government programs (largely led by FSA) as compared to approximately 337,000 principal operators who participated in conservation government programs (different aspects of these programs are led by either FSA or NRCS) (USDA NASS 2014). Further, in 2016, FSA administered over US\$7 billion in payments to over 1.5 million farms through the Agricultural Risk Coverage and Price Loss Coverage programs (USDA FSA 2018). This suggests a tremendous opportunity for FSA to strategically integrate climate information into their services, both formally and informally, to reach many of the land managers who never see an NRCS agent. Development of tools that appeal to FSA employees and that can ultimately provide climate information relevant to indemnities and disaster programs may help reach this large audience.

On Climate Advisor Interest. While there was moderate agreement between both agencies that there will be an increased need for agency programs due to changing weather patterns, NRCS respondents expressed much greater agreement that assisting producers with increased weather variability is part of their job, and that they have the knowledge, confidence, and technical skills to do so. While this finding may relate to the aforementioned variation in professional duties, it may also point to a missed opportunity among FSA field staff that could be further evaluated. A noteworthy number of employees in both agencies indicate a desire to provide weather and climate related services, but these employees often report a lack in confidence or insufficient skills to do so. This finding aligns with prior research on advisors' use of weather and climate tools and broader climate science literacy (Fraisse et al. 2009; Prokopy et al. 2013; Morris et al. 2014; Templeton et al. 2014; Wojcik et al. 2014).

Those respondents who reported using more climate and weather tools and a greater variety of weather information were more likely to report agreement with being knowledgeable, confident, and committed to the role of climate advisor, or to report neutrality with being knowledgeable and committed, which aligns with previous research on the topic (Church et al. 2018). It is unknown, however, if the use of resources leads to greater levels of confidence, or if confidence leads advisors to use of a large number of resources. We argue that confidence and commitment are bred, at least in part, by exposure to tools and resources. Without said exposure or training, there would be little basis for confidence. Furthermore, respondents may be more interested in playing this role once they discover that tools and resources are available to guide them through the process. To further explore this, there is an opportunity to train staff in use of each of these resources in their professional duties to promote awareness of these tools as professional resources, and evaluate the development of confidence as a climate advisor. Developing purposeful training resources for advisors, particularly in the realm of university extension, is currently being undertaken to improve the preparedness of advisors in providing climate and weather information and integrating relevant tools in planning processes (Fraisse et al. 2009; Grotta et al. 2013; Morris et al. 2014; Wojcik et al. 2014; Roesch-McNally et al. 2019).

Given that those who reported neutrality on the commitment and knowledge statement varied from the disagree group similarly (though less distinctly) to those who reported agreement, this group may be the ideal focus of many of these efforts. These individuals may be earlier in the stages of learning about climate and weather resources, or may be on the fence regarding the appropriateness of these resources in their professional role, but are not against these ideas outright and have expressed some concern regarding climate and weather threats. These neutral individuals may have tested the waters of many climate resources, but are not yet fully on board. Similar strategies could potentially move the needle from disagreement toward neutrality for certain individuals.

NRCS and FSA employees may not use these tools because they are not user friendly or ineffective in supporting decision making, as is often the case when end users are not engaged in the process of developing tools (Bartels et al. 2013; Beier et al. 2016). Breuer et al. (2010) found that cultivating a feedback loop between advisors and scientists can help improve the usefulness and usability of climate decision support tools, while Lemos et al. (2014) reiterated the importance of cultivating trust by creating a two-way communication strategy to increase perceptions of credibility and legitimacy in decision making contexts. Thus, new and existing tools and resources could integrate climate science in ways that help advisors do their job better, in alignment with locally relevant programs, processes, and decision making frameworks (Hibbs et al. 2014; Templeton et al. 2014; Prokopy et al. 2015b). A future focus on coproduction of these resources with USDA field staff could increase adoption of those resources in the future.

The varying effect of climate concern and climate belief on the commitment statement as compared to the knowledge and confidence statements is particularly noteworthy. Those who are more aware of and concerned about future impacts of climate change are more committed to supporting land managers in adapting to increasing weather variability, but they are also less confident in their ability to do so. A few potential explanations exist. First, these concerned yet unconfident respondents may find themselves disheartened or confused by the uncertainty and complexity of climate projections, as well as unsure of how to apply this information in a professional setting. Second, respondents may feel overwhelmed by the potential impacts of climate change and feel powerless to address impacts that they have seen or expect to see. This finding is consistent with literature that has found that too much fear of climate change can lead to inaction (O'Neill and NicholsonCole 2009; Randall 2009), and that concern about climate change can relate to avoidance of the topic in everyday thinking to prevent becoming too overwhelmed with fear and worry (Norgaard 2011). A more productive approach involves focusing on personally and locally relevant actions that incorporate existing systems (O'Neill and Nicholson-Cole 2009). Alternatively, those who hold beliefs that are farther from the scientific consensus on climate change will be expecting business as usual in the future. If they are confident in their current role related to assisting farmers with weather variability, then they anticipate that nothing will disrupt normal operations. Furthermore, ideologies that are associated with less belief in anthropogenic climate change are also associated with lack of concern about climate-related threats (Lucas and Davison 2018).

On the differing effect of agency, while the role of FSA employees involves providing a financial buffer to the impacts of weather variability and climate change, they may 
not recognize the relationship between the processing of claims and payments, which provides acute financial relief to climate and weather disasters, and supporting farmers in the context of climate change. The role of a NRCS employee more closely aligns with the technical side of addressing resource concerns, which are often closely intertwined with climate and weather variability. This variation in mission and roles between the two agencies could explain some of the differences between the two agencies related to concern, climate advisor interest, and preparedness.

Limitations. While many factors could have contributed to the variation in response rates between the two surveys, it is possibly due to the timing of survey administration. The FSA survey was administered during the very end of the Obama Administration and the NRCS survey was administered at the beginning of the Trump Administration. Given that transitions between administrations can be complex and involve shifting priorities, it is possible that this timing may have affected response rates. However, nonresponse bias testing indicated that, despite our sample being slightly older than the NRCS population, it was otherwise generally representative of the agency (Wiener et al. 2018). Furthermore, we acknowledge that our analysis is single series cross-sectional data, and therefore cannot meaningfully infer causation. While we have found a number of relationships between certain variables and outcomes, only longitudinal time-series data could elicit where such relationships are causal.

\section{Summary and Conclusions}

In this study, we identify several opportunities to increase the climate readiness of USDA field staff and the land managers they serve. A gap exists between concern regarding climate change and weather variability and confidence in providing support to address these impacts in a land management context. Training on climate science as it relates to professional duties of field staff could help close the gap between high desire and low confidence in playing the role of climate advisor.

Further, many of the tools and resources in this study were used by few respondents. Future development and improvement of tools and resources that are suited to supporting field staff could also help them feel equipped to handle climate and weather related challenges. Researchers, tool devel- opers, and organizations such as the USDA Climate Hubs can focus on developing tools and resources that seamlessly integrate climate information into professional services and programs, such as the NRCS Conservation Planning Process. These resources should be adaptable to focus on locally relevant climate threats, including those that have historically occurred and those that are expected to worsen based on climate projections. Trainings should avoid language that incites fear and focus instead on specific adaptive options that are relatable to personal and locally relevant experiences and can be reasonably implemented by land managers. The effectiveness of trainings and resources may be improved by bringing climate information and related adaptation strategies down to manageable levels that fit within the context of existing norms and practices. Further, to engage those who are less committed to providing climate-related services, mission-driven language such as "addressing resource concerns" (NRCS) or "reducing risk of crop loss" (FSA) could be used. Regarding confidence and interest in playing the role of climate advisor, these strategies could help push field staff from disagreement to neutrality, and from neutrality toward agreement, though the most receptive audiences are likely those who expressed agreement or neutrality with these statements.

Strategies should also consider the unique yet complementary missions and duties of these agencies. For example, resources developed for FSA could incorporate information on strategies that improve resilience in the face of extreme events. Land managers may be interested in this information immediately after an extreme event that prompts them to enter an FSA office to file a claim. However, development of these resources should consider that FSA agents are less confident and interested in being climate advisors, and perhaps frame the resources (i.e., fact sheets and handouts) in the context of providing disaster recovery assistance and prevention of future disaster impacts. Meanwhile, resources developed for NRCS should support existing agency goals such as soil health, and capitalize on the longer term nature of the NRCS Conservation Planning Process to incorporate longer term projections.

USDA field staff maintain a critical interface with land managers, from short-term disaster recovery to longer term conservation planning. Improving the ability of these staff to provide these services can only make working lands more productive and resilient in the face of a changing climate.

\section{Acknowledgements}

The authors of this study would like to acknowledge the valuable input from Mary Carey (former USDA Farm Service Agency [FSA] liaison to the Northeast Climate Hub, Washington, DC) and Rich Iovanna (senior agricultural economist, Washington, DC) of the FSA, and Mike Wilson (senior scientist, Lincoln, Nebraska), Lynn K. Knight (agricultural economist and co-director of the Northeast Climate Hub, Milton, Vermont), and Daniel Dostie (state resource conservationist, Harrisburg, Pennsylvania) of USDA Natural Resources Conservation Service (NRCS). We would also like to acknowledge the USDA Climate Hubs for their support of this research, and the NRCS and FSA employees who took the time to respond to our survey. Finally, we are grateful to the editorial staff at the Journal of Soil and Water Conservation, and to the two anonymous reviewers who provided thoughtful feedback on this manuscript.

\section{Disclosure}

The survey complies with exempt requirements under human subject research rules (UVM IRB Protocol Exemption Certification: CHRBSS: 17-0254).

\section{References}

AAPOR (The American Association for Public Opinion Research). 2016. Survey Outcome Rate Calculator 4.0. Oakbrook Terrace, IL: The American Association for Public Opinion Research.

Arbuckle Jr, J.G., L.W. Morton, and J. Hobbs. 2015. Understanding farmer perspectives on climate change adaptation and mitigation: The roles of trust in sources of climate information, climate change beliefs, and perceived risk. Environment and Behavior 47(2):205-234.

Bartels, W.L., C.A. Furman, D.C. Diehl, F.S. Royce, D.R. Dourte, B.V. Ortiz, and J.W. Jones. 2013. Warming up to climate change: A participatory approach to engaging with agricultural stakeholders in the Southeast US. Regional Environmental Change 13(1):45-55.

Beier, P., L.J. Hansen, L. Helbrecht, and D. Behar. 2016. A how-to guide for coproduction of actionable science. Conservation Letters 10(3):288-296.

Borelli, K.A., G.E. Roesch-McNally, J.D. Wulfhorst, S.D. Eigenbrode, G.G. Yorgey, C.E. Kruger, L.A. Bernacchi, L.L. Houston, and R.L. Mahler. 2018. Farmers' trust in sources of production and climate information and their use of technology. Journal of Extension 56(3):3FEA7. https://www.joe.org/joe/2018june/a7.php.

Breuer, N.E., H. Dinon, R. Boyles, and G. Wilkerson. 2011. Extension agent awareness of climate and new directions for research in North Carolina. Journal of Service Climatology 5(4):1-20. 
Breuer, N.E., C.W. Fraisse, and V.E. Cabrera. 2010. The Cooperative Extension Service as a boundary organization for diffusion of climate forecasts: A 5-year study. Journal of Extension 48(4):4RIB7.

Carlton, J.S., A.S. Mase, C.L. Knutson, M.C. Lemos, T. Haigh, D.P.Todey, and L.S. Prokopy. 2016. The effects of extreme drought on climate change beliefs, risk perceptions, and adaptation attitudes. Climatic Change 135(2):211-226.

Chatryachan, A.M., R.C. Erlebacher, N.T. Chaopricha, J. Chan, D. Tobin, and S.B. Allred. 2017. United States agricultural stakeholder views and decisions on climate change. Wiley Interdisciplinary Reviews: Climate Change 8(5):e467, doi:10.1002/wcc.469.

Church, S.P., M. Dunn, N. Babin, A.S. Mase, T. Haigh, and L.S. Prokopy. 2018. Do advisors perceive climate change as an agricultural risk? An in-depth examination of Midwestern U.S. ag advisors' views on drought, climate change, and risk management. Agriculture and Human Values 35(2) 349-365, doi:10.1007/s10460-017-9827-3.

Dillman, D.A., and J.D. Smyth. 2014. Internet, Phone, Mail, and Mixed-Mode Surveys. Hoboken, NJ: John Wiley \& Sons, Inc.

Fraisse, C.W., N.E. Breuer, D. Zierden, and K.T. Ingram. 2009. From climate variability to climate change: Challenges and opportunities to Extension. Journal of Extension 47(2):2FEA9.

Haigh,T., L.W. Morton, M.C.Lemos, C. Knutson, L.S. Prokopy, Y.J. Lo, and J.Angel. 2015. Agricultural advisors as climate information intermediaries: Exploring differences in capacity to communicate climate. Weather, Climate, and Society 7(1):83-93, doi:10.1175/WCAS-D-14-00015.1.

Hibbs, A.C., D. Kahl, L. PytlikZillig, B. Champion, T. AbdelMonem, T. Steffensmeier, C.W. Rice, and K. Hubbard. 2014. Agricultural producer perceptions of climate change and climate education needs for the central Great Plains. Journal of Extension 52(3):3FEA2.

Lemos, M.C., Y.J. Lo, C. Kirchhoff, and T. Haigh. 2014. Crop advisors as climate information brokers: Building the capacity of US farmers to adapt to climate change. Climate Risk Management 4:32-42, doi:10.1016/j. crm.2014.08.001.

Lucas, C.H., and A. Davison. 2018. Not 'getting on the bandwagon': When climate change is a matter of unconcern. Environment and Planning E: Nature and Space 0:1-21, doi:10.1177/2514848618818763.

Marx, S.M., E.U. Weber, B.S. Orlove, A. Leiserowitz, D.H. Krantz, C. Roncoli, and J. Phillips. 2007. Communication and mental processes:Experiential and analytic processing of uncertain climate information. Global Environmental Change 17:47-58, http://www.sciencedirect.com/ science/article/pii/S0959378006000847.

Mase, A.S., B.M. Gramig, and L.S. Prokopy. 2017. Climate change beliefs, risk perceptions, and adaptation behavior among Midwestern US crop farmers. Climate Risk Management 15:8-17.

Morris, L., M.A. Megalos, A. Vuola, D. Adams, and M. Monroe. 2014. Cooperative Extension and climate change: Successful program delivery. Journal of Extension 52(2):2COM3.

Morton, L.W., G. Roesch-McNally, and A.K. Wilke. 2017. Upper Midwest farmer perceptions: Too much uncertainty about impacts of climate change to justify changing current agricultural practices. Journal of Soil and Water Conservation 72(3):215-225, doi:10.2489/ jswc.72.3.215.

Norgaard, K. 2011. Climate denial: Emotion, psychology, culture and political economy. In Oxford Handbook on Climate Change and Society, eds. J.S. Dryzek, R.B. Norgaard, and D. Schlosberg, 399-413. Oxford: Oxford University Press.

O'Neill, S., and S. Nicholson-Cole. 2009. "Fear won't do it" promoting positive engagement with climate change through visual and iconic representations. Science Communication 30(3):355-379.

Prokopy, L.S., J.S. Carlton, J.G. Arbuckle, T. Haigh, M.C. Lemos, A.S. Mase, N. Babin, M. Dunn, J. Andresen, J. Angel, and C. Hart. 2015a. Extension's role in disseminating information about climate change to agricultural stakeholders in the United States. Climatic Change 130(2):261-272.

Prokopy, L.S., T. Haigh, A.S. Mase, J. Angel, C. Hart, C. Knutson, M.C. Lemos, Y.J. Lo, J. McGuire, L.W. Morton, and J. Perron. 2013. Agricultural advisors: A receptive audience for weather and climate information? Weather, Climate, and Society 5(2):162-167.

Prokopy, L.S., L.W. Morton, J.G. Arbuckle Jr., A.S. Mase, and A.K. Wilke. 2015b. Agricultural stakeholder views on climate change: Implications for conducting research and outreach. Bulletin of the American Meteorological Society 96(2):181-190.

Randall, R. 2009. Loss and climate change: The cost of parallel narratives. Ecopsychology 1(3):118-129.

Roesch-McNally, G.E., J. Benning, A.Wilke, J.Arbuckle, and L.W. Morton. 2019. University extension communities of practice: Learning, communicating, and engaging on climate change adaptation and mitigation in the United States Corn Belt. In Addressing Climate Change at the Community Level in the United States, eds. P.R. Lachapelle and D.E. Albrecht, 180-193. New York, NY: Routledge.

Schattman, R.E.,V.E. Mendez, S.C. Merrill, and A. Zia. 2018. A mixed methods approach to understanding farmer and agricultural advisor perceptions of climate change and adaptation in Vermont, United States. Agroecology and Sustainable Food Systems 42(2):121-148.

Stuart, D., R. Denny, M. Houser, A. Reimer, and S. MarquartPyatt. 2018. Farmers' selection of sources of information for nitrogen management in the US Midwest: Implications for environmental programs. Land-Use Policy 70:289-297.

Templeton, S.R., M.S. Perkin, H.D. Aldridge, W.C. Bridges Jr., and B.R. Lassiter. 2014. Usefulness and uses of climate forecasts for agricultural extension in South Carolina, USA. Regional Environmental Change 14(2):645-655.
USDA. 2017. Secretary Perdue Announces Creation of Undersecretary for Trade and USDA Reorganization. News release, May 11, 2017. Washington, DC: USDA. https://www.usda.gov/our-agency/reorganizing-usda.

USDA FSA (Farm Service Agency). 2017. Structure and Organization. Washington, DC: USDA Farm Service Agency. https://www.fsa.usda.gov/about-fsa/ structure-and-organization/index.

USDA FSA. 2018. 2016 ARC/PLC Payments by State. Washington, DC: USDA Farm Service Agency. https:// www.fsa.usda.gov/Assets/USDA-FSA-Public/usdafiles/ arc-plc/pdf/2016\%20ARC\%20PLC\%20payments\%20 April\%202018.pdf.

USDA NASS (National Agricultural Statistics Service). 2014. 2012 Census of Agriculture. Washington, DC: USDA National Agricultural Statistics Service. https://www. agcensus.usda.gov/Publications/2012/Full_Report/ Volume_1,_Chapter_1_US/usv1.pdf.

USDA NRCS (Natural Resources Conservation Service). 2017. Conservation Practice Physical Effects CPPE: NRCS Economics. USDA Natural Resources Conservation Service. https://www.nrcs.usda.gov/ wps/portal/nrcs/detail/national/technical/econ/ tools/?cid=nrcs143_009740.

USDA NRCS. 2018a. Environmental Quality Incentives Program. Washington, DC: USDA Natural Resources Conservation Service. https://www.nrcs.usda.gov/wps/ portal/nrcs/main/national/programs/financial/eqip/.

USDA NRCS. 2018b. People. Washington, DC: USDA Natural Resources Conservation Service. https://www. nrcs.usda.gov/wps/portal/nrcs/main/national/people/.

USGCRP (US Global Change Research Program). 2017. Climate Science Special Report: Fourth National Climate Assessment, Volume I, eds. D.J. Wuebbles, D.W. Fahey, K.A. Hibbard, D.J. Dokken, B.C. Stewart, and T.K. Maycock. Washington, DC: U.S. Global Change Research Program. doi:10.7930/J0J964J6.

Wiener, S., G.E. Roesch-McNally, and R.E. Schattman. 2018. National Survey of USDA Field Staff on Climate and Weather; Results from a survey of Natural Resources Conservation Service and Farm Service Agency Employees. Washington, DC: USDA Climate Hubs.

Wojcik, D.J., M.C. Monroe, D.C. Adams, and R.R. Plate. 2014. Message in a bottleneck? Attitudes and perceptions of climate change in the Cooperative Extension Service in the Southeastern United States. Journal of Human Sciences and Extension 2(1):51-70. 